\title{
Conexões
}

\section{Materiais didáticos e a educação física escolar}

\author{
Alexander Klein Tahara ${ }^{1}$ \\ Suraya Cristina Darido ${ }^{2}$ \\ Cristiano de Sant'nna Bahiax ${ }^{1}$
}

\section{RESUMO}

Os materiais didáticos são instrumentos que podem auxiliar o professor no processo de ensino e os alunos na aprendizagem sobre os conteúdos curriculares. O objetivo deste estudo foi discutir sobre a relação entre os materiais didáticos e a Educação Física escolar, apresentando trabalhos que refletem e argumentam a respeito desta relação, inclusive em alguns deles inserindo-se as tecnologias no desenvolvimento dos materiais. Espera-se que a produção dos materiais didáticos possa ser maior na Educação Física escolar para que o professor tenha mais recursos para ministrar os conteúdos curriculares nas aulas.

Palavras Chave: Material didático. Professor. Educação física. Escola.

\footnotetext{
${ }^{1}$ Universidade Estadual de Santa Cruz

${ }^{2}$ Universidade Estadual Paulista.

Recebido em: 26 jul. 2017

Aprovado em: 30 ago. 2017

Contato: alexipatinga@yahoo.com
} 


\section{Teaching materials and school physical education}

\section{A BStraCT}

Teaching materials are tools that can help the teacher in the teaching process and students in learning the curriculum contents. The aim of this study was to discuss the relationship between teaching materials and school Physical Education, presenting works that reflect and argue about this relationship, and that in some cases also include the technologies involved in the development of materials. We hope that the production of teaching materials may increase in Physical Education in order that teachers have more resources to teach the curriculum content in classes.

Keywords: Teaching materials. Teacher. Physical education. School.

\section{Materiales didácticos y la educación física escolar}

\section{RESUMEN}

Los materiales didácticos son herramientas que pueden ayudar al profesor en el proceso de enseñanza y a los estudiantes en el aprendizaje del contenido de los programas. El objetivo de este estudio fue analizar la relación entre los materiales didácticos y la educación física escolar, presentando obras que reflexionen y discuten sobre esta relación, incluyendo la inserción de algunas tecnologías en el desarrollo de materiales. Se espera que la producción de materiales didácticos pueda ser mayor en educación física para que el profesor tenga más recursos para enseñar el contenido curricular en las clases.

Palabras Clave: Materiales didácticos. Profesor. Educación física. Escuela. 


\section{INTRODUÇÃO}

Atualmente, em âmbito educacional, discute-se bastante a questão referente aos materiais didáticos atrelados aos diferentes componentes curriculares, como em Vilaça (2009) com o ensino das Línguas Estrangeiras, Bittencourt (2010) e os livros didáticos em História (VAZ et al., 2012) ao focarem a elaboração de materiais didáticos inclusivos para o ensino da Biologia, Rodrigues e Gazire (2012) no uso de material didático manipulável no ensino e aprendizagem da Matemática, entre outros estudos.

Entretanto, no caso da Educação Física, Darido et al. (2010); Impolcetto (2012); Ginciene e Matthiesen (2015) referenciam que há ainda pouca expressividade destes materiais didáticos na área escolar, havendo necessidade de fomentar esta produção.

Zabala (1998) entende que os materiais didáticos são todos os recursos que podem proporcionar aos professores respaldos, referências e critérios para tomar decisões, tanto na fase de planejamento, na intervenção direta no processo de ensino e aprendizagem, bem como em sua avaliação. Desta forma, torna-se possível considerar os materiais didáticos como os meios que auxiliam os professores nas diferentes fases de planejamento, execução e avaliação do processo de ensino e aprendizagem dos diferentes componentes curriculares.

A inovação do ensino a partir da elaboração de novos materiais pedagógicos, como afirma Sacristán (2000), deve ser uma estratégia muito bem pensada para que possa haver uma melhoria e qualidade dos sistemas educativos. Desta forma, torna-se possível que os professores busquem auxílio em diferentes tipos de materiais para planejar suas ações, direcionar seus trabalhos, aprofundar seus conhecimentos e favorecer o processo de ensino e aprendizagem dos alunos.

Diante da atual fase tecnológica e moderna atrelada às Tecnologias da Informação e Comunicação (TIC), pode-se facilmente pensar enquanto possíveis materiais didáticos os mais variados tipos de softwares, jogos digitais, redes sociais e blogs, dispositivos móveis (smartphones, iPads, etc.), entre outras inúmeras possibilidades. Entretanto, não se deve esquecer que tradicionalmente nas instituições escolares o quadro negro, giz, caderno, caneta, lápis e borracha, bem como os inúmeros livros-texto foram e ainda são exemplos de materiais didáticos frequentemente adotados em âmbito educacional.

Conforme evidencia Bittencourt (2010), embora ainda haja muitas discussões contraditórias acerca dos livros didáticos, este objeto tem se constituído na atualidade como o material didático mais presente nas salas de aula dos diferentes níveis de ensino das escolas. A autora esclarece que "[...] a presença dos livros didáticos pode ser identificada ao se acompanhar a história da educação escolar e suas práticas no decorrer dos dois últimos séculos" (BITTENCOURT, 2010, p. 545). 
Diante desta hegemonia comentada acima, Godoi e Padovani (2009) entendem que o livro didático não deve ser o único material a ser utilizado pelo professor, havendo necessidade de se pensar na produção de novos materiais didáticos digitais que possam favorecer boas e variadas situações de aprendizagem. Afinal, as tecnologias estão completamente inseridas no dia a dia das pessoas, haja vista o número expressivo de indivíduos que fazem uso delas constantemente em seu cotidiano.

Diante disso, imagina-se que as múltiplas possibilidades de TIC podem ser capazes de oferecer boas oportunidades para o desenvolvimento de novas práticas pedagógicas dos professores. Acredita-se também que a elaboração e implementação de materiais didáticos, seja de natureza digital ou não, podem ser capazes de fazer referências e abordar os diferentes conteúdos que se apresentam na Educação Física escolar.

Assim sendo, a intenção deste artigo é promover uma reflexão acerca da presença (ou ausência) de materiais didáticos em aulas de Educação Física nas escolas, pensando-se nas possibilidades educacionais que este tipo de material pode acarretar para o professor, para os alunos e para o contexto escolar de forma geral.

\section{Métodos}

Este estudo é de natureza qualitativa, uma vez que a intenção foi realizar uma pesquisa bibliográfica sobre a relação dos materiais didáticos e a área da Educação Física escolar, visando qualificar e discutir os artigos científicos, capítulos de livro, teses e demais trabalhos publicados sobre esta temática.

Foi feito uma busca utilizando-se o Google Acadêmico para direcionar a trabalhos que versam sobre a relação dos materiais didáticos e a Educação Física escolar. A pesquisa na base de dados foi feita com a inclusão das seguintes palavras chave: Materiais Didáticos, Escola, Tecnologia da Informação e Comunicação (TIC), Educação Física, Educação Física escolar, e uma combinação entre elas. Todos os trabalhos que realçavam tal relação foram considerados para análise e discussão neste artigo.

A importância da realização da pesquisa bibliográfica, como salientam AlvesMazzotti e Gewandsznajder (2001), deve ser atribuída a uma revisão crítica das teorias e pesquisas no processo de produção de novas reflexões e pensamentos, sendo aspecto essencial na construção de novos conhecimentos capazes de influenciar e contribuir para o desenvolvimento teórico-metodológico na referida área de estudo. 


\section{Análise e Discussão}

A utilização dos materiais didáticos no contexto da Educação Física escolar pode ser muito importante no processo educacional, uma vez que estes materiais podem ser instrumentos que auxiliam na aprendizagem dos alunos sobre os conteúdos da referida área.

A ausência de materiais didáticos de qualidade para os professores de Educação Física torna-se uma das grandes dificuldades apresentadas pelos profissionais da área, gerando ainda mais dificuldades para os professores no interior das aulas na escola, como evidenciam Gaspari et al. (2006); Darido et al. (2010); Rodrigues e Darido (2011).

Rodrigues e Darido (2011) enfocam que, diferente das demais disciplinas do currículo escolar, no que tange à Educação Física a discussão e pesquisas relacionadas à elaboração e utilização de materiais didáticos, como livros-didáticos, blogs, softwares, ainda é considerada pequena, merecendo olhares de pesquisadores e estudiosos que se dedicam ao tema.

Acerca dessa discussão, Impolcetto (2012) esclarece que há necessidade de uma maior ênfase na elaboração de materiais didáticos para os professores de Educação Física escolar. Tal material pode auxiliar no desenvolvimento das aulas, partindo-se do princípio de que torna-se importante:

[...] que a organização curricular dos conteúdos e a construção desse tipo de material possa acontecer de modo colaborativo entre o meio acadêmico e os professores que atuam nas escolas, valorizando suas experiências e conhecimentos (IMPOLCETTO, 2012, p.17).

Diante da perspectiva de um trabalho realizado de forma colaborativa, pode-se imaginar que haja sucesso na elaboração de um material didático, por exemplo atrelado às TIC, sendo produzido a partir das experiências e vivências dos professores, organizando e refletindo sobre a possibilidade de ensino e aprendizagem dos conteúdos curriculares.

No caso de um trabalho colaborativo na área da Educação Física escolar, em que possa haver participação dos professores em discussões que perpassam a elaboração, colaboração na implementação em aulas e/ou avaliação destes professores acerca do uso de materiais didáticos, pesquisas como Rodrigues e Darido (2011), Silva (2012), Impolcetto (2012), Rufino (2012), Diniz e Darido (2015), Gemente (2015), entre outros, realçam como se deu processo educacional no que tange à abordagem de alguns conteúdos da referida área de conhecimento. Menciona-se que em alguns destes estudos houve a utilização de determinada TIC durante o processo de construção destes materiais. 
No caso da elaboração de livros didáticos, Rodrigues e Darido (2011) idealizaram um livro didático de basquetebol, sendo que o mesmo sofreu uma avaliação por parte de cinco professores de Educação Física. Um aspecto importante neste processo avaliativo foi referente à identificação e aceitação do material didático, onde os professores demonstraram interesse pela possibilidade de possuir um livro didático de apoio ao trabalho docente. Entretanto, eles foram bastante críticos frente ao livro didático de basquetebol ao enumeraram vantagens, como o fato de possuir uma sequência organizada dos conteúdos, além de conter imagens, textos e exercícios que podem ser amplamente utilizado, mas também apontaram desvantagens acerca de sua utilização em âmbito escolar, como o elevado volume de discussões e debates propostos, bem como a dificuldade que tal tipo de material poderia trazer se não permitisse a adaptação, ou seja, um livro didático fechado dificultaria o trabalho docente.

Impolcetto (2012) comenta que a organização curricular e o livro didático são temas pouco abordados nas pesquisas da área de Educação Física escolar. Desta forma, objetivou-se em sua pesquisa a elaboração e análises acerca do processo de construção coletiva com seis professores de Educação Física de um livro didático de voleibol, apresentando uma proposta de organização curricular desse conteúdo do $6^{\circ}$ ao $9^{\circ}$ ano do Ensino Fundamental. Ao término dos encontros, as aulas elaboradas para o $6^{\circ}$ ano foram aplicadas por uma das professoras do grupo e observadas pela pesquisadora, constandose que o livro didático, o qual foi produto da construção coletiva, resultou em possibilidades concretas para a melhoria da prática pedagógica dos professores de Educação Física diante da abordagem do conteúdo referente ao voleibol.

Rufino (2012) propôs um curso de formação continuada com professores de escolas estaduais de São Paulo, no intuito de se fazer análises acerca do processo de construção coletiva e participativa de um livro didático sobre o conteúdo das lutas para o Ensino Médio. Após a elaboração do livro didático, dois professores participantes da pesquisa puderam aplicar o material em suas aulas, possibilitando novas perspectivas para práticas pedagógicas relacionadas às lutas para as aulas de Educação Física escolar. Ademais, todo o processo de elaboração foi permeado de ações participativas e colaborativas, possibilitando que durante a formação continuada dos professores, fosse respeitado e valorizado os seus saberes docentes, suas experiências práticas e cotidianas do dia a dia no "chão da escola" em meio às aulas escolares.

Considerando-se o novo contexto social, uma alternativa interessante para auxiliar o professor seria por meio do uso das TIC. Ginciene e Matthiesen (2014) comentam que ainda são poucos os trabalhos que relacionam as TIC à área da Educação Física, sendo que cabe ao professor de Educação Física a tentativa em “[...] desenvolver esse tema da virtualização e das tecnologias em suas aulas, já que, além de ser de extrema importância, é algo que faz parte do cotidiano dos alunos [...]" (GINCIENE; MATTHIESEN, 2014, p. 120). 
Embora ainda haja esta carência no que se relaciona ao uso das TIC em contexto escolar, alguns estudos versam sobre a utilização de determinadas tecnologias no processo de elaboração e implementação de um material didático. As múltiplas variedades de TIC podem oferecer oportunidades para o desenvolvimento de novas práticas pedagógicas, como também, para a elaboração de materiais didáticos que consigam abordar os conteúdos da Educação Física, por meio das diferentes linguagens e suas combinações.

Súnega et al. (2012) produziram e implementaram materiais didáticos audiovisuais abordando as relações de temas transversais com o conteúdo do basquetebol, em aulas de Educação Física do $9^{\circ}$ ano do Ensino Fundamental. Os resultados foram satisfatórios em relação à ampliação dos conteúdos e a relação dos temas transversais, proporcionando aprendizagens significativas para os alunos. Desta forma, torna-se importante haver mais estratégias de uso e implementação de diferentes materiais didáticos para o ensino dos conteúdos da Educação Física escolar.

Silva (2012) desenvolveu um blog relacionado ao ensino da capoeira, sendo realizados grupos focais com professores e alunos de Educação Física. Ambos concordaram com a utilização deste blog como um material didático, no sentido de tornar-se um facilitador do ensino da capoeira. Tal blog pode ser considerado como uma ferramenta tecnológica de fácil usabilidade, ou seja, tem facilidade e praticidade para a realização de uma determinada tarefa, com eficácia e simplicidade, podendo ser utilizado por professores no intuito de compartilhar informações e conhecimentos com seus pares e alunos a respeito de conteúdos norteadores da área da Educação Física.

Desta forma, imagina-se que os blogs podem ser utilizados de diferentes formas no contexto escolar, podendo ser criados pelos professores servindo de apoio pedagógico para o acompanhamento e andamento de suas aulas junto aos alunos. Podem também ser criados pelos alunos e de forma coletiva junto aos professores, onde cada turma pode ter o seu próprio blog, relatando as experiências nas vivências escolares, bem como a realização de pesquisas acerca dos temas trabalhados em aula e servindo como um mediador pedagógico, entre outras possibilidades.

Seja usando o blog e/ou outras opções de TIC, as mesmas reúnem elementos que disponibilizam ao professor diferentes oportunidades de referenciar qualquer um dos conteúdos da Educação Física por meio de diferentes facetas digitais, as quais incluem a imagem, o som, o texto e o vídeo, enriquecendo o ambiente de aprendizagem.

Nesse sentido, Ambrós, Foguet e Rodríguez (2013) sugerem que os webs e blogs podem ajudar na tarefa de ensinar os conteúdos da Educação Física nas escolas. Além disso, trabalhar com os aplicativos celulares e as redes sociais podem também servir como instrumentos importantes nos dias atuais para se atingir esse intento junto aos alunos, uma vez que os mesmos estão constantemente "conectados" às tecnologias. 
No caso de mais artigos encontrados neste estudo e que traçam relações entre os materiais didáticos e as tecnologias, Diniz e Darido (2015) propuseram a elaboração e avaliação de um material didático complementar ao Currículo de Educação Física do Estado de São Paulo, em uma linguagem digital que pudesse subsidiar o trabalho do professor no desenvolvimento do conteúdo de danças folclóricas proposto para o $7^{\circ}$ ano do ensino fundamental.

O blog educacional foi avaliado por seis professores de Educação Física, ressaltam Diniz e Darido (2015), sendo que dois participantes deste grupo ministraram aulas de danças folclóricas a partir do conteúdo proposto no blog, experimentando em situações reais de ensino as possibilidades da proposta. A avaliação do material didático produzido mostrou que ele pode contribuir para que haja a inserção das danças folclóricas na escola, uma vez que oferece subsídios para o professor abordar este tema por meio das três dimensões dos conteúdos.

Gemente (2015) desenvolveu de maneira colaborativa um software junto a professores de Educação Física para o processo de ensino e aprendizagem do atletismo na escola. Houve a participação inicial de 21 professores de Educação Física da rede municipal, levantando-se as dificuldades e necessidades desses professores no trabalho com o atletismo nas aulas de Educação Física.

Foi desenvolvido o software ATLETIC, o qual aborda as provas do salto em altura, salto com vara, lançamento do dardo, lançamento do disco, lançamento do martelo e arremesso do peso, a partir das sugestões, necessidades e interesses apresentados pelos professores. Posteriormente, 13 professores que participaram da primeira etapa da pesquisa elaboraram e interviram nas escolas com a implementação do ATLETIC nas aulas, sendo que tal software e outras tecnologias podem apresentar contribuições para o processo de ensino e aprendizagem do atletismo na Educação Física escolar (GEMENTE, 2015).

Ginciene e Matthiesen (2015) elaboraram um material didático virtual com base na internet e organizado, mais precisamente, na plataforma de Educação a Distância conhecida como Moodle. Os autores localizaram, organizaram e selecionaram jogos virtuais, vídeos, sites, blogs e redes sociais relacionados à prova dos 100 metros rasos, disponíveis na internet, compondo um banco de dados que tende a facilitar um possível trabalho de pesquisa por parte do professor de Educação Física em abordar este conteúdo. A ideia foi produzir um material didático diferente de um livro convencional, havendo possibilidades de ser visto e utilizado pela internet, além da gratuidade.

O Quadro 1 retrata em linhas gerais como vem ocorrendo a produção de materiais didáticos no âmbito da Educação Física escolar, referenciando os (poucos) estudos e autores que se dispuseram a tratar do tema. Convém ressaltar que espera-se que essa produção científica possa ser cada vez mais significativa, no propósito de que 
haja divulgação para os professores e direções pedagógicas, para que os materiais produzidos possam ser implementados, desenvolvidos e discutidos junto aos alunos.

Quadro 1 - Estudos/Autores que propuseram materiais didáticos para Educação Física Escolar

\begin{tabular}{|l|l|}
\hline \multicolumn{1}{|c|}{ Estudos/Autores } & \multicolumn{1}{c|}{ Descrição do material didático proposto } \\
\hline Rodrigues; Darido (2011) & $\begin{array}{l}\text { Livro didático para ensino do Basquetebol - avaliação } \\
\text { por um grupo de professores de Educação Física }\end{array}$ \\
\hline Silva (2012) & $\begin{array}{l}\text { Blog educacional para ensino da Capoeira - grupos } \\
\text { focais com professores e alunos de Educação Física com } \\
\text { e sem experiência na Capoeira }\end{array}$ \\
\hline Impolcetto (2012) & $\begin{array}{l}\text { Livro didático para ensino do Voleibol - construção } \\
\text { coletiva e organização curricular deste conteúdo do 6 } \\
9^{\circ} \text { ano do Ensino Fundamental }\end{array}$ \\
\hline Súnega et al. (2012) & $\begin{array}{l}\text { Materiais audiovisuais abordando as relações de alguns } \\
\text { temas transversais com o conteúdo do basquetebol nas } \\
\text { aulas do 9 ano do Ensino Fundamental }\end{array}$ \\
\hline Rufino (2012) & $\begin{array}{l}\text { Livro didático para ensino das Lutas - construção } \\
\text { coletiva para ensino do conteúdo no Ensino Médio }\end{array}$ \\
\hline Diniz; Darido (2015) & $\begin{array}{l}\text { Blog educacional destinado para ensino das Danças } \\
\text { Folclóricas para alunos do 7 ano do Ensino } \\
\text { Fundamental }\end{array}$ \\
\hline Gemente (2015) & $\begin{array}{l}\text { Elaboração colaborativa do Software ATLETIC para } \\
\text { ensino do Atletismo }\end{array}$ \\
\hline Ginciene; Matthiesen (2015) & $\begin{array}{l}\text { Banco de dados virtual feito na Plataforma Moodle sobre } \\
\text { aspectos da prova dos 100 metros rasos do Atletismo }\end{array}$ \\
\hline
\end{tabular}

Tomando-se por base esses trabalhos mencionados acima, torna-se possível imaginar que para se concretizar inovações pedagógicas dentro das aulas de Educação Física escolar, é pertinente que possa haver a participação dos professores da educação básica, seja nos processos de elaboração, implementação e/ou avaliação dos materiais didáticos, para que a experiência colaborativa possa favorecer qualitativamente o ensino e aprendizagem dos conteúdos.

Contudo, além da produção de materiais didáticos, é preciso que os professores assumam a responsabilidade de utilizá-los de maneira crítica e criativa. Ressalta-se que o envolvimento e a participação na elaboração de materiais didáticos pode colaborar para o desenvolvimento e reflexão das novas práticas, incentivando o diálogo entre os professores e permitindo a divulgação do material produzido.

Ainda mais com as possibilidades de atrelar as opções variadas de tecnologias atuais - sejam as redes sociais, blogs, celulares, jogos virtuais, computadores, entre outros - nos processos de elaboração e implementação destes materiais no cotidiano escolar, como aspecto importante que deva ser tratado e problematizado junto aos alunos durante o desenvolvimento das aulas. 


\section{Considerações Finais}

O intuito deste ensaio foi refletir sobre a relação que se estabelece entre os materiais didáticos e a Educação Física escolar. Infelizmente, esta referida área de conhecimento, de uma maneira geral, ainda não se apropriou da utilização sistemática de diferentes tipos de materiais didáticos. Embora seja perceptível na literatura um crescente no número de pesquisas, ainda há uma carência de estudos que versam sobre o tema e apresentem recursos que possam efetivamente auxiliar os professores no processo de ensino-aprendizagem.

Espera-se que a elaboração e utilização de materiais didáticos sejam cada vez mais um processo constante e contínuo por parte dos pesquisadores, professores, alunos e direções pedagógicas, em que possa favorecer o ensino e a aprendizagem dos diferentes conteúdos pertencentes à Educação Física escolar.

Ademais, almejando-se colaborar com a construção de novas estratégias pedagógicas destinadas aos professores, a possibilidade em se desenvolver um material didático digital acaba por permitir a utilização das TIC em meio educacional, no propósito de que estas tecnologias possam ser conectadas, exploradas e vivenciadas pelos alunos durante o desenvolvimento dos conteúdos nas aulas.

Entende-se que seja papel da comunidade científica e acadêmica de forma geral concentrar esforços durante as importantes fases de elaboração, implementação e avaliação de materiais didáticos, inseridos no contexto das aulas de Educação Física escolar. O processo educativo torna-se bastante complexo na atualidade, onde os recursos tecnológicos estão cada vez mais inseridos em nosso cotidiano, e desta forma, exigindo que os professores disponham cada vez mais de recursos e instrumentos que o auxiliem na (difícil) tarefa de ensinar a Educação Física nas escolas.

\section{REFERÊNCIAS}

ALVES-MAZZOTTI, Alda Judith; GEWANDSZNAJDER, Fernando. O método nas ciências naturais e sociais: pesquisa quantitativa e qualitativa. 2. ed. São Paulo: Pioneira Thomson Learning, 2001.

AMBRÓS, Queralt Prat; FOGUET, Oleguer Camerino; RODRÍGUEZ, Jordi Lluís Coiduras. Introducción de las TIC em educación física: estudio descriptivo sobre la situación actual. Apunts: educación física y deportes, Barcelona, n. 113, p. 37- 44, jul./sept. 2013.

BITTENCOURT, Circe Maria Fernanda. Livros didáticos de história: práticas e formação docente. In: DALBEN, Ângela et al. (Org.). Convergências e tensões no 
campo da formação e do trabalho docente: ensino de história. Belo Horizonte: Autêntica, p. 544-565, 2010.

DARIDO, Suraya Cristina et al. Livro didático na Educação Física escolar: considerações iniciais. Motriz, Rio Claro, v. 16, n. 2, p. 450-457, abr./jun. 2010.

DINIZ, Irlla Karla dos Santos; DARIDO, Suraya Cristina. Blog educacional e o ensino das danças folclóricas nas aulas de Educação Física: aproximações a partir do currículo do estado de São Paulo. Movimento, Porto Alegre, v. 21, p.701-716, 2015.

GASPARI, Telma Cristina et al. A realidade dos professores de Educação Física na escola: suas dificuldades e sugestões. Revista Mineira de Educação Física, Viçosa, v.14, n.3, p.109-137, 2006.

GEMENTE, Florence Rosana Faganello. Atletismo na educação física escolar: a elaboração colaborativa do software Atletic. 2015. 217f. Tese (Doutorado em Desenvolvimento Humano e Tecnologias) - Universidade Estadual Paulista Júlio de Mesquita Filho, Rio Claro, 2015.

GINCIENE, Guy; MATTHIESEN, Sara Quenzer. Deve-se utilizar as tecnologias da informação e comunicação em aulas de educação física? Arquivos em Movimento, Rio de Janeiro, v.10, n. 2, p.111-128, jul./dez. 2014.

GINCIENE, Guy; MATTHIESEN, Sara Quenzer. Utilizando o moodle na Educação Física: sobre um material didático virtual para o ensino do atletismo. Motrivivência, Florianópolis, v. 27, n. 44, p. 109-124, 2015.

GODOI, Kátia Alexandra de; PADOVANI, Stephania. Avaliação de material didático digital centrada no usuário: uma investigação de instrumentos passíveis de utilização por professores. Produção, v. 19, n. 3, p. 445-457, set./dez. 2009.

IMPOLCETTO, Fernanda Moreto. Livro Didático como Tecnologia Educacional: uma proposta de construção coletiva para a organização curricular do conteúdo voleibol. 2012. 321f. Tese (Doutorado em Desenvolvimento Humano e Tecnologias) Universidade Estadual Paulista Júlio de Mesquita Filho, Rio Claro, 2012.

RODRIGUES, Heitor de Andrade; DARIDO, Suraya Cristina. O livro didático na Educação Física escolar: a visão dos professores. Motriz, Rio Claro, v. 17 n. 1, p. 48-62, jan./mar. 2011.

RODRIGUES, Fredy Coelho; GAZIRE, Eliane Scheidt. Reflexões sobre uso de material didático manipulável no ensino de matemática: da ação experimental à 
reflexão. Revemat: revista eletrônica de educação matemática, Florianópolis, v. 7, n. 2, p.187-196, 2012.

RUFINO, Luiz Gustavo Bonatto. "Campos de luta”: o processo de construção coletiva de um livro didático na Educação Física no Ensino Médio. 2012. 364f. Dissertação (Mestrado em Desenvolvimento Humano e Tecnologias) - Universidade Estadual Paulista, Rio Claro, 2012.

SACRISTÁN, José Gimeno. O currículo: uma reflexão sobre a prática. 3. ed. Porto Alegre: Artmed, 2000.

SILVA, Luciana Maria Fernandes. O ensino da capoeira na Educação Física escolar: blog como apoio pedagógico. 2012. 175f. Dissertação (Mestrado em Desenvolvimento Humano e Tecnologias) - Universidade Estadual Paulista, Rio Claro, 2012.

SÚNEGA, Paula Beatriz Camargo et al. Luz, câmera, educação e ... cesta: produção e implementação de materiais audiovisuais para o ensino do basquetebol e dos temas transversais nas aulas de Educação Física. Arquivos em Movimento, Rio de Janeiro, v.8, n.2, p.44-64, jul/dez. 2012.

VAZ, José Murilo Calixto et al. Material didático para ensino de biologia: possibilidades de inclusão. Revista Brasileira de Pesquisa em Educação em Ciências, v. 12, n. 3, p. 81-104, 2012.

VILAÇA, Márcio Luiz Corrêa. O material didático no ensino de língua estrangeira: definições, modalidades e papéis. Revista Eletrônica do Instituto de Humanidades, v. 8, n. 30, p.1-14, jul./set. 2009.

ZABALA, Antoni. A prática educativa: como ensinar. Porto Alegre: Artmed, 1998. 